\title{
Response of Schizophrenic Patients to Dynamic Facial Expressions: An Event-Related Potentials Study
}

\author{
Mayuko Fukuta $^{a}$ Eiji Kirino $^{a, b}$ Reiichi Inoue ${ }^{b}$ Heii Arai ${ }^{a, b}$ \\ a Department of Psychiatry, School of Medicine, Juntendo University, Tokyo, and b Juntendo Institute of Mental \\ Health, Koshigaya, Japan
}

\section{Key Words}

Schizophrenia - Facial expression · Movement .

Event-related potential $\cdot \mathrm{N} 200 \cdot \mathrm{P} 100 \cdot$ Face N170

\begin{abstract}
Objective: Patients with schizophrenia have an impaired ability to respond to faces and may specifically show an impaired response to dynamic facial expressions. Here we investigated the responses of schizophrenic patients and healthy controls to dynamic facial images using event-related potentials (ERPs). Methods: We showed 13 schizophrenic patients and 13 healthy controls visual stimuli comprising facial expressions that continually changed from neutral to emotional. Results: N200 latencies and P100-N200 peak-topeak amplitudes in controls were prolonged or greater for dynamic emotions in comparison with those for static stimuli, but the group with schizophrenia showed no significant differences in responses to dynamic and static emotions. A significant negative correlation was observed between N200 latencies for dynamic negative emotion and PANSS (positive and negative syndrome scale) general psychopathology scale scores. Conclusions: A combination of hypersensitivity to static emotions and hyposensitivity to dynamic emotions in people with schizophrenia might underlie the absence of differences in response to these stimuli. A tendency in the
\end{abstract}

schizophrenic group to hypersensitivity to static emotions might arise from the enhanced fear and arousal characteristics of this group; their hyposensitivity to dynamic emotions might result from controlled attentional bias away from facial expressions to reduce fear and anxiety.

ㄷ) 2014 S. Karger AG, Basel

\section{Introduction}

The brain's response to emotional expression might be expected to differ among different psychiatric populations not only because of condition-related changes in emotional circuits but also because these individuals differ in the strategies they use to view other people's faces [1]. Schizophrenia is reportedly associated with functionally important abnormalities in face processing [2] in the domains of facial identifying [3-6], emotion recognition $[1,7-9]$ and complex social judgment [10-12], leading to social communication disorders. Schizophrenic patients may have visual scanning and cognitive strategies for emotions that differ from those of healthy subjects [13, 14].

Based on studies using intracranial recording or neuroimaging, neurons that respond specifically to faces are thought to have loci in the bilateral fusiform gyrus/

\begin{tabular}{ll}
\hline KARGER & $\begin{array}{l}\text { (C) 2014 S. Karger AG, Basel } \\
0302-282 X / 14 / 0701-0010 \$ 39.50 / 0 \quad \text { Karger }\end{array}$ \\
$\begin{array}{l}\text { E-Mail karger@karger.com } \\
\text { www.karger.com/nps }\end{array}$ & $\begin{array}{l}\text { This is an Open Access article licensed under the terms of the } \\
\text { Creative Commons Attribution-NonCommercial 3.0 Un- } \\
\text { ported license (CC BY-NC) (www.karger.com/OA-license), } \\
\text { applicable to the online version of the article only. Distribu- } \\
\text { tion permitted for non-commercial purposes only. }\end{array}$
\end{tabular}

Eiji Kirino

Juntendo University Shizuoka Hospital

1129 Nagaoka

Izunokuni-shi, Shizuoka 4102211 (Japan)

E-Mail ekirino@juntendo.ac.jp 
inferior temporal gyrus [15-20]. In addition, the basal ganglia and insula cortex appear to be consistently implicated in disgust recognition, and the amygdala is implicated in fear $[21,22]$, along with other emotions. In schizophrenia, the fusiform gyrus has a number of structural $[23,24]$ and functional $[24,25]$ abnormalities in neuroimaging studies, and the insula [26-28], basal ganglia $[28,29]$ and amygdala $[30,31]$ are structurally and functionally abnormal. In neurophysiological studies, a face-related event-related potential (ERP), the N170, shows abnormalities such as attenuated amplitude or prolonged latency in individuals with schizophrenia [24, 32-40].

One issue that remains to be addressed is whether impairment in facial identification by schizophrenic patients arises from abnormalities in more basic visual processing, leading to a bottom-up contribution. Another question is whether the impairment is specific to faces or occurs in the processing of all complex images. In their evaluation of schizophrenic patients, Chen et al. [41] used brief stimulus presentations of a line-drawn face (13-104 $\mathrm{ms}$ ) displayed upright or inverted to prevent the normal formation of general facial impressions. They found that the schizophrenic patients showed a significantly reduced face inversion effect compared with normal controls, primarily because of significantly lower accuracy in detecting upright faces. These results indicate that at the initial visual detection stage, facial processing is inefficient in schizophrenia [41].

Hypoactivation of the amygdala has been reported in schizophrenic patients in evaluations of blood flow changes on functional MRI (fMRI), elicited by fearful versus neutral faces [31]. However, more recent work using fMRI [42-44] has suggested that there may be hyperactivation of the amygdala to neutral faces in schizophrenia, accounting for the apparent deficit in blood flow when comparing fearful and neutral faces. The equivalent response of the amygdala to neutral and fearful faces may impede their distinction and could potentially lead to either over- or under-attribution of fear, depending on the context. The finding that the amygdala is abnormally activated in schizophrenia is concordant with the enhanced fear and arousal characteristic of patients experiencing psychotic symptoms [22].

As noted, however, the specificity of the impairment is in question. Is it a 'differential deficit' specific to facial emotion processing, or does it reflect general cognitive impairment and/or problems in face identity processing? Facial processing impairment specific to affect [22] seems most likely, given that studies that control statistically for facial identity recognition impairment still demonstrate a facial affect recognition deficit $[4,6]$ and that some studies have found impairment in facial affect recognition despite intact facial identity recognition [10].

Core areas that are particularly strongly associated with social cognition or complex social judgment include the superior temporal sulcus, amygdala and medial prefrontal cortex [45]. The superior temporal sulcus, amygdala and prefrontal cortex all have reduced gray matter volumes in schizophrenia in the majority of MRI studies that have quantified these brain regions [29, 30, 46, 47]. The white matter tracts linking the frontal lobes with the temporal and parietal lobes are also structurally abnormal on MRI in schizophrenic patients [48], suggesting a functional disconnection of the frontal and temporal lobe regions [22]. Some evidence implicates brain function differences in schizophrenia during social judgment of faces, with blood flow abnormalities while assessing trustworthiness identified in the amygdala [48, 49], ventrolateral prefrontal cortex [12] and medial orbitofrontal cortex [49].

Thus, a range of neural abnormalities in schizophrenia in regions associated with face processing, emotional recognition and social cognition has been described. However, conventional studies often use static images as visual stimuli, and few studies have employed dynamic facial expressions. In our daily lives, we continuously interpret the movement of others and put these actions into context [50], interpreting a person's mental state through changes in their facial expression and monitoring their focus of attention through gaze shifts during a social interaction [51]. No matter how affective the stimuli employed in the physiological experiments are, static images cannot fully reproduce the dynamic facial expressions that individuals actually see in real-life situations.

Studies that use fMRI or magnetoencephalography (MEG) have demonstrated that the origin of neurons responding to eye movements is an area corresponding to the middle temporal area/visual area (MT/V5) or a region centered in the superior temporal sulcus [19, 50, 52-54]. We previously reported that individuals with schizophrenia specifically have difficulty with recognizing eye movements rather than with processing a static face [55]. Thus, we hypothesized that dynamic processing in investigations of abnormalities of emotion processing in schizophrenia would reflect clinical observations better than studies using static stimuli. Here we present ERP results using dynamic images as stimuli in schizophrenic patients and healthy controls with the aim of investigating the brain response during the processing of faces. 
Table 1. Demographic and clinical characteristics of the test sample

\begin{tabular}{|c|c|c|}
\hline & $\begin{array}{l}\text { Schizophrenic } \\
\text { patients }\end{array}$ & Controls \\
\hline Subjects, $\mathrm{n}$ & 13 & 13 \\
\hline $\mathrm{M} / \mathrm{F}$ ratio & $8 / 5$ & $8 / 5$ \\
\hline Age, years & $33.3 \pm 6.2$ & $32.4 \pm 5.2$ \\
\hline Education, years & $13.6 \pm 2.0$ & $17.0 \pm 2.0$ \\
\hline \multicolumn{3}{|l|}{ Subtype, $\mathrm{n}$} \\
\hline Disorganized & 5 & \\
\hline Paranoid & 5 & \\
\hline Catatonic & 0 & \\
\hline Residual & 1 & \\
\hline Unclassified & 2 & \\
\hline Age at onset, years & $22.2 \pm 6.0$ & \\
\hline Illness duration, years & $11.1 \pm 6.4$ & \\
\hline Antipsychotic medication, mg & $7.8 \pm 5.0(13 / 13)$ & \\
\hline Atypical & $5.3 \pm 3.7(8 / 13)$ & \\
\hline Atypical + typical & $12.3 \pm 4.7(5 / 13)$ & \\
\hline \multicolumn{3}{|l|}{ Antiparkinsonian, mg } \\
\hline Biperiden hydrochloride & $2.0 \pm 0.89(6 / 13)$ & \\
\hline Benzodiazepines, mg & $11.2 \pm 3.1(3 / 13)$ & \\
\hline \multicolumn{3}{|l|}{ PANSS scores } \\
\hline Positive & $12.5 \pm 4.8$ & \\
\hline Negative & $17.8 \pm 4.9$ & \\
\hline General psychopathology & $30.3 \pm 7.1$ & \\
\hline Total & $60.6 \pm 14.5$ & \\
\hline
\end{tabular}

Values are numbers or means \pm SD. Antipsychotic medication: risperidone equivalent. Benzodiazepines: diazepam equivalent.

\section{Methods}

\section{Subjects}

This study was approved by the ethics review committee at Juntendo University. The subjects were 13 schizophrenic patients ( 8 men and 5 women, mean age $33.3 \pm 6.2$ years, all right-handed) and 13 age- and sex-matched healthy controls (mean age $32.4 \pm 5.2$ years, all right-handed). While attempts were made to match the groups for years of education, this proved to be difficult as schizophrenic patients who are more likely to require hospitalization tend to have an early age of onset [56], which interferes with schooling. As such, controls had significantly more years of education $(17.0 \pm 2.0, \mathrm{p}<0.001)$ compared with patients $(13.6 \pm 2.0)$. Patients were recruited from among outpatients at Juntendo Koshigaya Hospital in Saitama, Japan, and healthy controls were recruited from the staff of the same hospital. In the patient group, the mean disease duration was $11.1 \pm 6.4$ years, and the mean dose of the drug used for treatment (risperidone equivalent) was $7.8 \pm$ $5.0 \mathrm{mg}$ (table 1). All patients were judged to be in good physical health on the basis of medical history, physical examination and laboratory measures. None of the subjects had a history of electro- convulsive shock treatment, alcohol or other drug abuse (DSM-IV criteria) [57], addiction, or a neurological illness affecting the central nervous system. All subjects reported having normal visual acuity. For each patient, the DSM-IV [57] diagnosis and the PANSS (positive and negative syndrome scale) [58] score were determined by a structured psychiatric interview and by a review of the patient's medical charts. The PANSS is an instrument that uses a semistructured interview and a 7-point scale to rate 30 symptoms that are common in schizophrenia and other mental disorders. The mean PANSS scores were $12.5 \pm 4.8$ (positive scales), $17.8 \pm$ 4.9 (negative scales), $30.3 \pm 7.1$ (general psychopathology scales), and $60.6 \pm 14.5$ (total score). Before the start of the experiment, we explained its objectives and methods to each participant, and all participants gave written informed consent.

\section{Stimuli and Procedure}

We used Japanese and Caucasian facial expressions of emotion (JACFEE) and neutral faces (JACNeuF) [59, 60]. These images were developed by Ekman et al. [61] and are considered the international standards for use in studies involving the recognition of facial expressions. Although the original images included hair, the hair portions were omitted in this study. For one image (S1) to change to another image (S4), transitional images (S2 and S3) were created using algorithms in image processing software (Adobe ImageReady ${ }^{\mathbb{B}}$ ). In this experiment, one stimulus unit consisted of four images. The visual effect of dynamic images was achieved by continuous presentation of images S1-S4. S1 was presented for 500 $\mathrm{ms}$, and S2, S3 and S4 were then each presented for $100 \mathrm{~ms}$ so that the presentation of one unit took a total of $800 \mathrm{~ms}$. The stimulus onset asynchrony between units was set to $1,700-1,800 \mathrm{~ms}$, and the interstimulus interval was set to $900-1,000 \mathrm{~ms}$. The stimulus onset asynchrony and interstimulus interval varied randomly from trial to trial to diminish the effects of habituation or prediction by the subjects.

The subjects were asked to evaluate the identical dynamic images to stimuli used in the ERP experiments on a questionnaire using a point scale of $1-5$ (visual analog scale) to indicate how clearly they had recognized the emotion shown in each of the images. The JACFEE/JACNeuF has the following 6 facial expression categories: neutral, contempt, sad, happy, disgust, and fear. Because questionnaire results showed that it was difficult for the subjects to distinguish between contempt and sad and between disgust and fear, we categorized contempt and sad as subtle negative emotions. We were also interested in evaluating how patients processed such subtle expressions. Thus, we classified the expressions, except for the neutral ones, into 3 categories as follows: contempt and sad were categorized as low emotion, disgust and fear as negative emotion and happy as positive emotion (fig. 1). We used 37 types of facial expressions with the faces of 4 Japanese men, 3 Japanese women, 4 Caucasian men, and 3 Caucasian women. We also used static facial expressions with radially moving concentric circles in the background as control stimuli, following Puce et al. [19]. All facial expressions used for the dynamic faces were reused for the static facial expressions. For stimuli consisting of static emotions, the face remained unchanged. However, the radial background rings changed between S1 and S4 and appeared to move continuously inward. The radial background rings remained unchanged during the dynamic facial expression stimuli. This background motion was designed to activate brain regions that were sensitive to motion per se and to diminish their contribution to the 
Fig. 1. Facial expression categories.

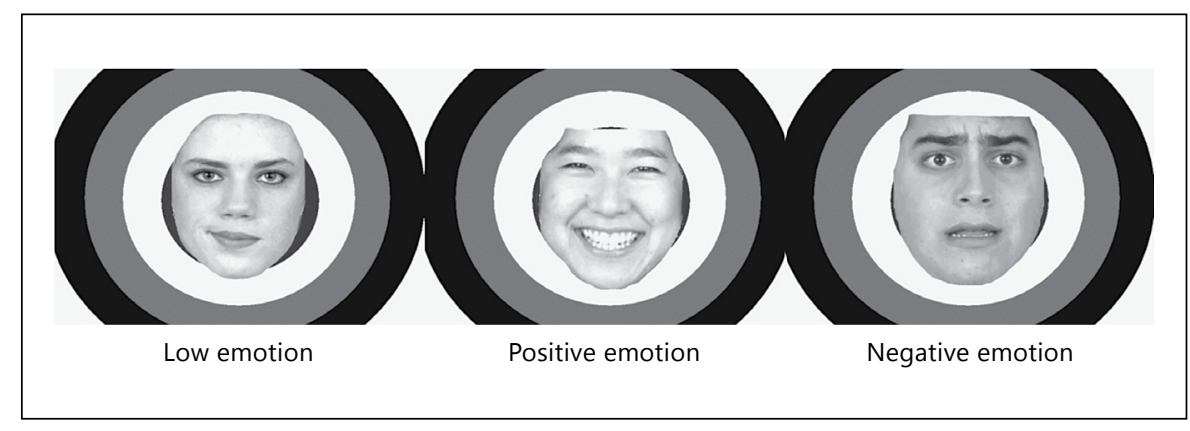

activation differences between viewing dynamic facial expressions and static faces [19].

A total of 6 types of stimuli were used with low, negative and positive emotion in the dynamic emotion stimuli (dynamic facial expressions with nonmoving backgrounds) and then again in the static emotion stimuli (nondynamic facial expressions with moving backgrounds). Thus, $2 \times 3$ types of stimuli were used: dynamic low, static low, dynamic negative, static negative, dynamic positive, and static positive.

A visual stimulus device, the Multi Trigger System ${ }^{\circledR}$ (MTS Systems Corporation, Tokyo, Japan), was used to present the stimuli. The stimuli were presented on the monitor of a Windows-based personal computer that subtended a visual angle of $7 \times 7^{\circ}$. All stimuli had the same luminance, contrast and size. The distance between the subject's eyes and the display was $150 \mathrm{~cm}$. Stimuli for each of the 6 facial expression categories were presented randomly 112 times, and the total experimental duration was $1,176 \mathrm{~s}$ ( 2 blocks with a 5 -min intermission). All 37 types of facial expressions were equally used and presented, but the presentation order was pseudo-randomized. The subjects were asked to pay attention to the stimuli, but no overt or covert response to any stimulus was required.

\section{Electroencephalogram Measurements}

Using an electrode cap (Electrode-Cap ${ }^{\circledR}$, Electro-Cap International Inc., Eaton, Ohio, USA) and a reference electrode on the nasal apex, an electroencephalogram was derived from the 25 sites of the International 10-20 system: Fp1, Fp2, F7, F3, Fz, F4, F8, T3, C3, Cz, C4, T4, T5, P3, Pz, P4, T6, O1, Oz, O2, PO3, PO4, $\mathrm{PO} 7, \mathrm{PO} 8$, and $\mathrm{POz}$. Electroencephalography was recorded using SYNAFIT EE2500 ${ }^{\circledR}$ (NEC Corporation, Tokyo, Japan) in a shielded room. The sampling rate was set at $500 \mathrm{~Hz}$ for all measurements. The impedances of all electrodes were maintained below $5 \mathrm{~K} \Omega$. The online filter was set at $0.5-60 \mathrm{~Hz}$, and an offline filter was not used. A bipolar electrode pair was placed above and over the outer canthus of the right eye for electrooculogram (EOG) recording.

\section{ERP Waveform Analysis}

An electroencephalography reader station (SynaViewer ${ }^{\circledR}$ ES5003; GE Marquette, Tokyo, Japan) and a software for ERP analysis (EPLYZER II ${ }^{\circledR}$; Kissei Comtec Co. Ltd., Tokyo, Japan) were used for waveform analysis. One ERP epoch was 1,500 ms long, including a $100-\mathrm{ms}$ period before the onset of a stimulus. The mean potential during a $100-\mathrm{ms}$ interval before the start of S1 presentation served as the baseline.

ERP of Facial Movement in Schizophrenia
The root mean square voltage of the EOG channel was computed to identify and discard epochs associated with eye movements and blink artifacts. The raw EEG data in each epoch were inspected manually during review on the monitor screen. Epochs contaminated by EOGs, blinks or muscle artifacts exceeding an artifact rejection threshold of $\pm 80 \mu \mathrm{V}$ at any electrode were omitted from the analysis. All single-trial epochs were baseline corrected prior to the subsequent process. Artifact-free epochs were segregated by stimulus code and averaged by subject. There was no significant difference in the amount of accepted epochs between groups and between the stimulus codes. Before examining the components of the S2 response, we examined those of S1 (Static S1-P100, S1-N100 and S1-P200) as reference data. Peak amplitudes and latencies of Static S1-P100, S1-N100 and S1-P200 were detected within the latency ranges of $100-150 \mathrm{~ms}, 150-200 \mathrm{~ms}$ and 210-260 ms, respectively.

\section{Identification of ERP Components of the Moving S2-S4}

Response

Regardless of the types of emotion, positive and negative ERP components were observed at 70-120 ms (moving S2-P100) and 150-200 ms (moving S2-N200), respectively, after the facial expressions began to change, i.e. after moving S2-S4 began (fig. 2-7). These components might be equivalent to the previously reported P100 and N200 (face N170) components for the recognition of static face stimuli. The baseline-to-peak amplitudes and latencies of moving S2-P100 and moving S2-N200 were measured. We measured the peak at the start of the S2 presentation (i.e. when a facial expression began to change) as the base point. The peak-to-peak amplitudes between the P100 and N200 components were also measured. We chose the time windows for the ERP components of interest after we observed the waveforms of individual subjects and the averaged waveforms; we wanted the windows to cover the peaks of as many subjects as possible. The measurements at the P3, P4, O1, O2, T5, T6, PO7, and PO8 leads, which most clearly identified these components, were analyzed statistically.

\section{Statistical Analysis}

SPSS statistical software for Windows (SPSS, Chicago, Ill., USA) was used for all analyses. For statistical analysis of each moving S1-ERP component, three-way analyses of variance (ANOVAs) with repeated measures on two factors were performed with three factors, namely, group, emotion (neutral S1 of all dynamic emotions and emotional $\mathrm{S} 1$ of all static emotions) and electrode. For the moving S2-ERP component, four-way ANOVAs with repeated measures on three factors were per- 


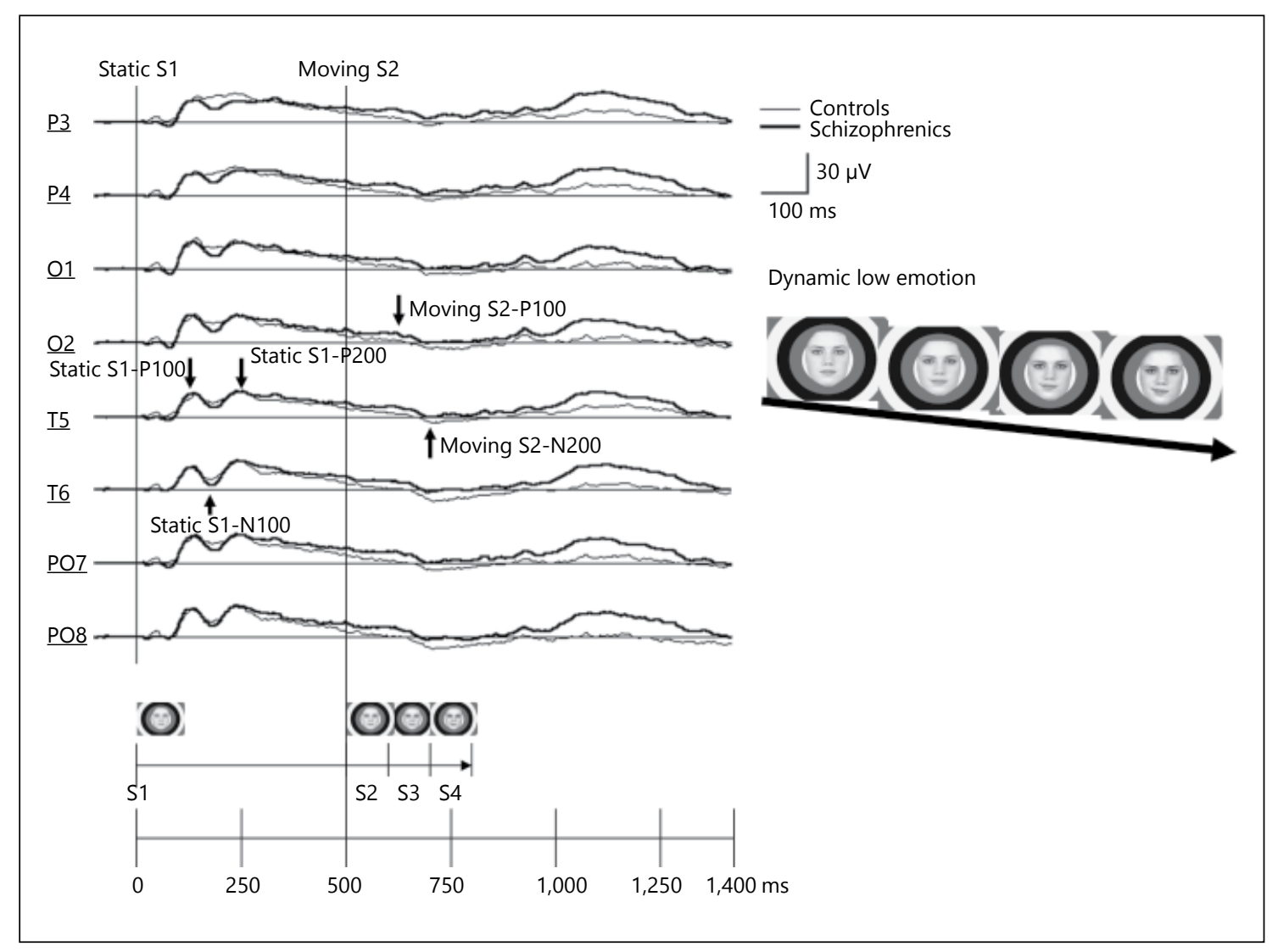

Fig. 2. Grand average waveforms for dynamic low emotion.

formed with four factors, namely, group (controls and patients), dynamics (dynamic and static emotion), emotion (low, negative and positive emotion), and electrode (P3, P4, O1, O2, T5, T6, PO7, and PO8). Reduced degrees of freedom (Greenhouse-Geisser) were used when appropriate to counter violations of the sphericity assumption underlying ANOVA with repeated measures (epsilon values were provided). Alpha values of 0.05 were considered significant. The Bonferroni test was performed for multiple comparisons, and alpha values of 0.05 were considered significant after the confidence interval was adjusted by Bonferroni correction using SPSS.

The correlations among ERP results (values averaged across electrodes) of the 6 types of stimuli and the subtotal scores of positive, negative and general psychopathology scales of PANSS of the patients were computed using Pearson's correlation coefficient. For these calculations, the standard of statistical significance was $0.5 / 6$ of alpha values (two-tailed) by Bonferroni correction to adjust for multiplicity in correlations between each PANSS score and the 6 types of stimuli.

Because the neural responses for static faces and dynamic stimuli differ in terms of loci and pathways, processing the response data in a unified statistical analysis may be considered problematic. However, others have established statistical analysis of the responses to static facial expressions as part of the assessments of dynamic stimuli in previous reports $[19,53,54,58,62]$.

\section{Results}

\section{Preliminary Data for the Static S1 Response}

Results of ANOVA revealed no main group effects or interactions between group and emotion for amplitude and latencies of Static S1-P100, S1-N100, S1-P200, or S1-P100-N100 or S1-N100-P200 peak-to-peak amplitudes.

\section{Results of ANOVA Analyses of Moving S2-ERP \\ Components}

Moving S2-P100 Amplitude

The electrode effect $\left(\mathrm{F}_{7,168}=4.763, \mathrm{p}=0.003, \varepsilon=0.461\right)$ was significant $(\mathrm{P} 3>\mathrm{T} 6$ in post hoc tests, $\mathrm{p}=0.018)$. An interaction was observed among dynamics, electrode and group $\left(\mathrm{F}_{7,168}=2.896, \mathrm{p}=0.022, \varepsilon=0.618\right)$. No other effects or interactions, including group effect $\left(\mathrm{F}_{1,24}=4.043\right.$, $\mathrm{p}=0.056)$, group-dynamics $\left(\mathrm{F}_{1,24}=0.579, \mathrm{p}=0.454\right)$, group-emotion $\left(\mathrm{F}_{2,48}=0.252, \mathrm{p}=0.778\right)$, and group-electrode $\left(\mathrm{F}_{7,168}=1.888, \mathrm{p}=0.134, \varepsilon=0.461\right)$ interactions, were significant. 


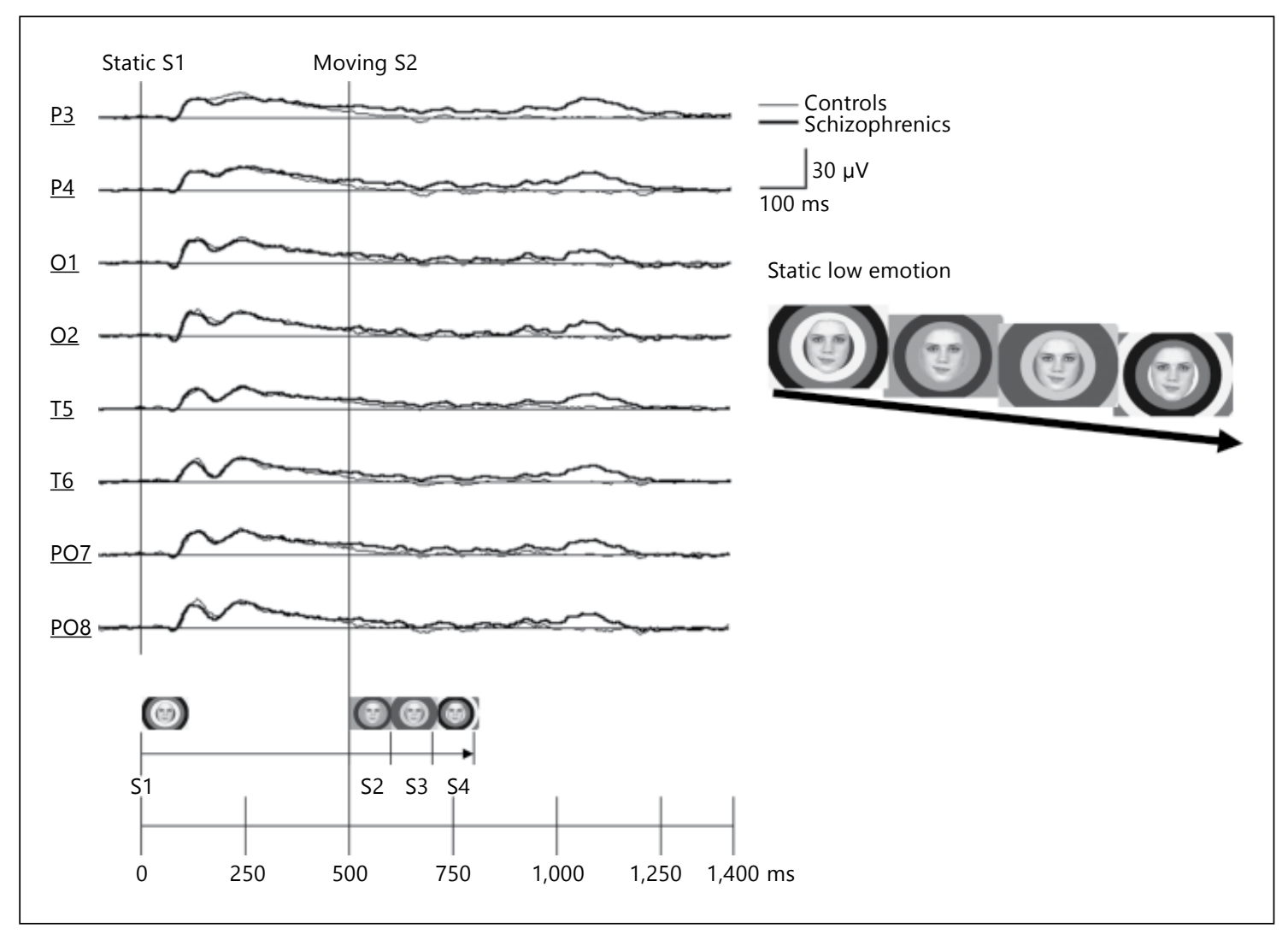

Fig. 3. Grand average waveforms for static low emotion.

\section{Moving S2-P100 Latency}

The group effect $\left(\mathrm{F}_{1,24}=8.880, \mathrm{p}=0.007\right)$ was significant (controls $>$ patients). No main effects or interactions, including group-dynamics $\left(\mathrm{F}_{1,24}=0.021, \mathrm{p}=0.887\right)$, group-emotion $\left(\mathrm{F}_{2,48}=0.884, \mathrm{p}=0.420\right)$ and group-electrode $\left(\mathrm{F}_{7,168}=1.334, \mathrm{p}=0.269, \varepsilon=0.453\right)$ interactions, were significant.

\section{Moving S2-N200 Amplitude}

The dynamics effect $\left(\mathrm{F}_{1,24}=4.381, \mathrm{p}=0.047\right)$ was significant (dynamic $>$ static in post hoc tests, $\mathrm{p}=0.047$ ). The electrode effect $\left(\mathrm{F}_{7,168}=6.385, \mathrm{p}<0.001, \varepsilon=0.483\right)$ was also significant $(\mathrm{P} 3<\mathrm{O} 2, \mathrm{P} 3<\mathrm{T} 6$ and $\mathrm{PO} 8$ in post hoc tests; $\mathrm{p}=0.007, \mathrm{p}=0.029$ and $\mathrm{p}=0.021$, respectively). An interaction was observed between dynamics and electrode $\left(\mathrm{F}_{7,168}=3.037, \mathrm{p}=0.043, \varepsilon=0.363\right)$. Post hoc tests revealed that amplitudes for dynamic emotions were greater than those for static emotions on the level of T5 $(\mathrm{p}=0.028)$, T6 $(\mathrm{p}=0.004)$ and PO8 $(\mathrm{p}=0.036)$. An interaction was observed among dynamics, emotion and electrode $\left(\mathrm{F}_{14,336}=3.140, \mathrm{p}=0.025, \varepsilon=0.243\right)$. No other effects or interactions, including group effect $\left(\mathrm{F}_{1,24}=2.457\right.$, $\mathrm{p}=0.130)$, group-dynamics $\left(\mathrm{F}_{1,24}=0.973, \mathrm{p}=0.334\right)$, group-emotion $\left(\mathrm{F}_{2,48}=0.014, \mathrm{p}=0.987\right)$, and group-electrode $\left(\mathrm{F}_{7,168}=2.153, \mathrm{p}=0.092, \varepsilon=0.483\right)$ interactions, were significant.

\section{Moving S2-N200 Latency}

An interaction was observed between group and dynamics $\left(\mathrm{F}_{1,24}=7.650, \mathrm{p}=0.011\right)$. Post hoc tests revealed that latencies for dynamic emotions were prolonged in comparison with those for static emotions in controls $(p=0.029)$, but there were no differences between dynamic and static stimuli in participants with schizophrenia (fig. 8a). Another interaction was observed between emotion and dynamics $\left(\mathrm{F}_{2,48}=3.759, \mathrm{p}=0.030\right)$. Post hoc tests revealed that latencies for low emotion were prolonged in comparison with those for negative $(\mathrm{p}=0.041)$ or positive $(\mathrm{p}=0.007)$ emotions in the dynamic category, but there were no differences among static stimuli. No other effects or interactions, including group effect $\left(\mathrm{F}_{1,24}=0.068, \mathrm{p}=0.797\right)$, group-emotion $\left(\mathrm{F}_{2,48}=0.290\right.$, $\mathrm{p}=0.693, \varepsilon=0.774)$ and group-electrode $\left(\mathrm{F}_{7,168}=1.464\right.$, $\mathrm{p}=0.214, \varepsilon=0.634)$ interactions, were significant. 


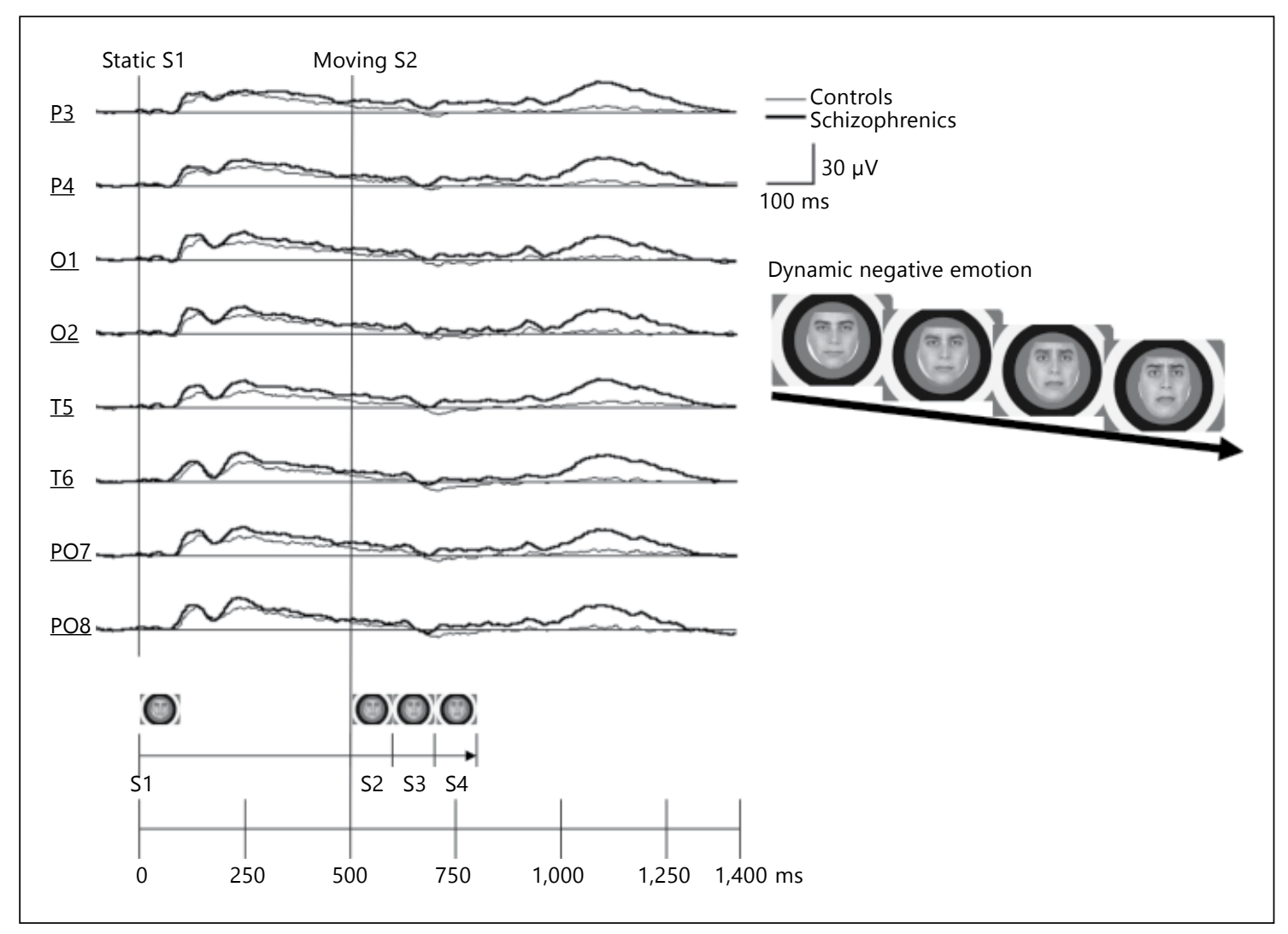

Fig. 4. Grand average waveforms for dynamic negative emotion.

Moving S2-P100-N200 Peak-to-Peak Amplitude

The electrode effect $\left(\mathrm{F}_{7,168}=5.029, \mathrm{p}=0.002, \varepsilon=0.505\right)$ was significant ( $\mathrm{T} 5<\mathrm{PO} 7$ and $\mathrm{T} 6<\mathrm{PO} 8$ in post hoc tests; $p=0.014$ and $p=0.011$, respectively). An interaction was observed between group and dynamics $\left(\mathrm{F}_{1,24}=9.212, \mathrm{p}=\right.$ 0.006). Post hoc tests revealed that amplitudes for dynamic emotions were significantly greater than those for static emotions in controls $(\mathrm{p}=0.009)$, but there were no significant differences between dynamic and static stimuli in patients (fig. 8b). Furthermore, an interaction was observed between dynamics and emotion $\left(\mathrm{F}_{2,48}=5.703, \mathrm{p}=\right.$ 0.006). Post hoc tests revealed that amplitudes for low emotion were greater than those for negative emotions in the dynamic stimulus group $(\mathrm{p}=0.016)$ and that amplitudes for static emotion were greater than those for dynamic emotions in the negative emotion category $(\mathrm{p}=$ $0.010)$. An interaction was also observed between dynamics and electrode $\left(\mathrm{F}_{7,168}=4.619, \mathrm{p}=0.005, \varepsilon=0.428\right)$. Post hoc tests revealed that amplitudes for dynamic emotions were greater than those for static ones on the level of T6 $(\mathrm{p}=0.026)$. In addition, an interaction was observed among dynamics, emotion and electrode $\left(\mathrm{F}_{14,336}=6.826\right.$, $\mathrm{p}<0.001, \varepsilon=0.434)$. No other effects or interactions, including group effect $\left(\mathrm{F}_{1,24}=0.409, \mathrm{p}=0.528\right)$, group-emotion $\left(\mathrm{F}_{2,48}=0.515, \mathrm{p}=0.601\right)$ and group-electrode $\left(\mathrm{F}_{7,168}=\right.$ $0.502, \mathrm{p}=0.712, \varepsilon=0.505)$ interactions, were significant.

\section{Results of Correlation Analysis}

A significant negative correlation was observed between moving S2-N200 latencies for dynamic negative emotion and PANSS general psychopathology scale scores $(r=-0.699, p=0.008$; fig. 9). There were no significant correlations between the other scores of PANSS and ERP amplitudes or latencies.

\section{Discussion}

In the present study, moving S2-N200 amplitudes for dynamic emotions were significantly greater than those for static emotions across the subjects of both groups. In a study using MEG, Watanabe et al. [50] compared responses to static faces with radially moving backgrounds, as in our study, with the response to eye movements. They 


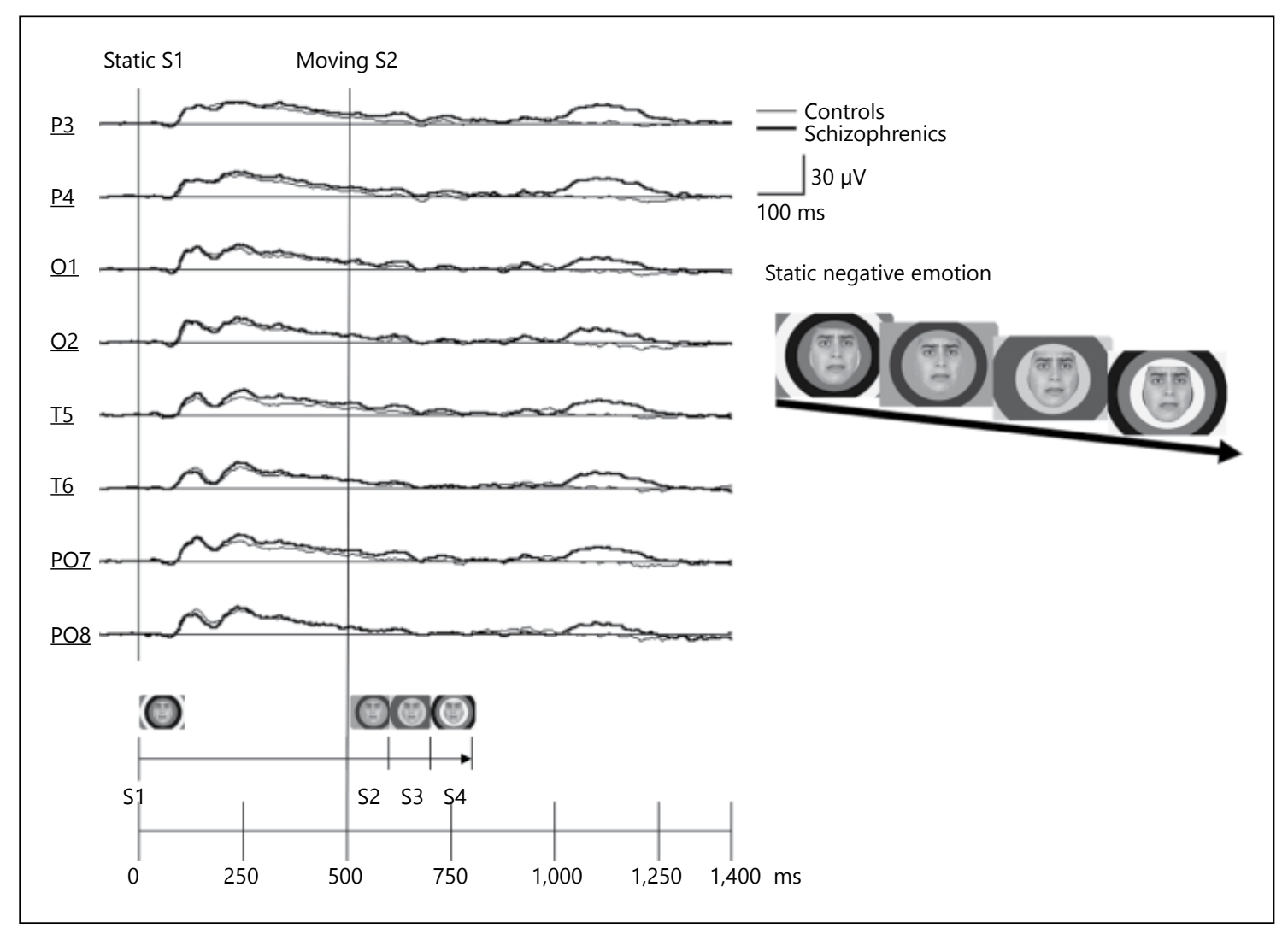

Fig. 5. Grand average waveforms for static negative emotion.

reported that an MEG component, $1 \mathrm{M}$, to moving eyes was significantly longer in latency and smaller in amplitude than that seen to radially moving backgrounds and that these stimuli were processed via different pathways; the areas that were responsive to eye motion could be distinguished from the areas that were responsive to radial motion. We found it of particular interest that moving S2-N200 latencies and moving S2-P100-N200 peak-topeak amplitudes in controls were prolonged or greater for dynamic emotions in comparison with those for static ones, but that the patients with schizophrenia showed no significant differences between the two. These findings might reflect the fact that information processing for dynamic facial expressions involves more complex and larger resources of information than for static facial expressions for controls compared with patients.

The studies using static stimuli reported that patients with schizophrenia may have cognitive strategies for emotions that differ from those of nonschizophrenic subjects $[13,14]$. When viewing faces, healthy individuals fixate their gaze on salient features such as the eyes, mouth and ears [63]. Conversely, deluded schizophrenia pa- tients pay relatively less attention to these facial features [64]. Abnormalities in the visual scanpath are more apparent during the processing of emotional facial expressions, and schizophrenic patients fixate less on the salient features when viewing expressions with negative [14] and even positive affect [65]. Green et al. $[14,66]$ reported restricted scanning (reduced number and duration of fixations, shorter scanpath length and shorter duration of fixations to facial features) in a group of schizophrenic participants. Their findings suggested a controlled attentional bias away from the feature areas of negative facial expressions and an attentional style of 'vigilance-avoidance' for threatening social information in deluded schizophrenia. As a result, they inferred that threat-related stimuli may automatically capture attention during the early stage of information processing, followed by conscious avoidance of these stimuli during later stages of directed attention to reduce anxiety $[14,66]$. These previous findings suggesting different cognitive strategies of patients for static faces or facial expressions may apply when viewing dynamic emotions. However, the previous studies concerning facial identification or emotion recog- 


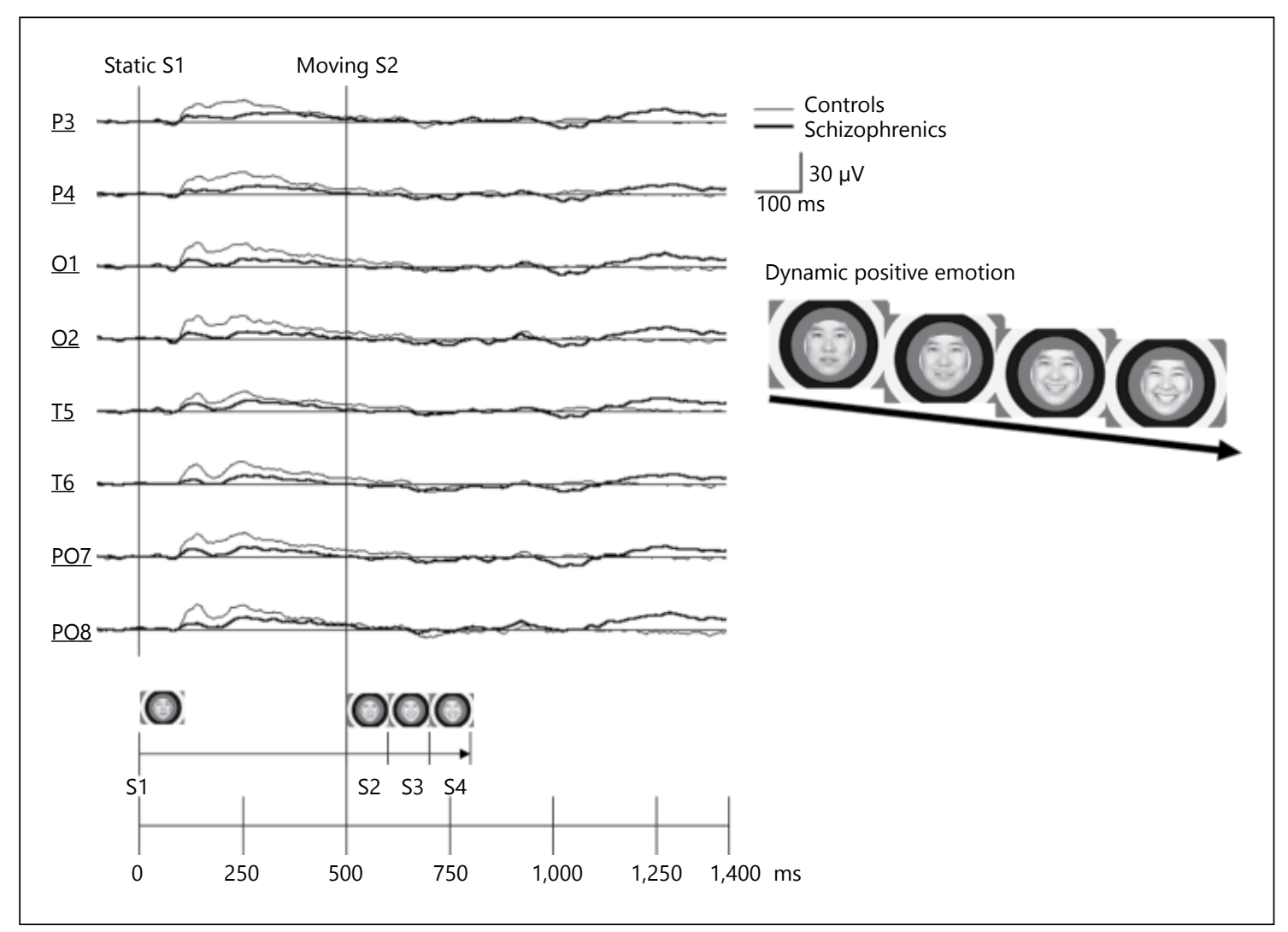

Fig. 6. Grand average waveforms for dynamic positive emotion.

nition employed various methodologies, including MRI volumetry, diffusion tensor imaging, fMRI, visual scanpath, or MEG, which have different time and spatial resolutions from ERP. It is therefore best to interpret the results of the present study independently.

Few studies have examined the ability of schizophrenic patients to respond to dynamic facial expressions, with most investigations using static facial expressions as the visual stimuli. However, Cabral-Calderin et al. [67] did perform the Emotional Expression Multimorph Task in schizophrenic patients using morphed images (changing facial expressions from 0 to $100 \%$ emotional in 21 steps every $0.2 \mathrm{~s}$ ). Although recognition of surprise, fear and anger was significantly reduced in the patient group compared with the healthy controls, the significance of the difference disappeared after 3 months of treatment with quetiapine [67]. Radua et al. [1] reported that fMRI revealed reduced activity, especially in the amygdala and hippocampus, in blood oxygenation level-dependent responses of patients to morphed fearful faces compared with healthy volunteers. In addition to using the standard approach of fMRI analysis, they applied principal compo- nent analysis to identify seven orthogonal factors from fearful faces and included them in the fMRI analysis. This principal component analysis-based fMRI analysis revealed activation of the left frontal pole for the 'brows' factor that was not detected in healthy volunteers. These authors suggested that this activation reflects an allocation of attentional resources to signals of potential threat [1]. In another study from Suzuki and Kirino [55] using fMRI, attenuated activity of the right superior temporal region and transverse temporal gyrus and overactivity in the left amygdala were recorded for moving eyes.

In the present study, there were no differences in the moving S2-N200 latencies or moving S2-P100-N200 peak-to-peak amplitudes between dynamic and static emotions in schizophrenic patients. By contrast, in controls, these measures for dynamic emotions were significantly prolonged or greater in comparison with those for static stimuli. The tendency to hyposensitivity to dynamic emotions among schizophrenic patients might be attributable to 'a controlled attentional bias away from the dynamic facial expressions' [14] to reduce fear and anxiety. On the other hand, in the context of the hyperactiva- 


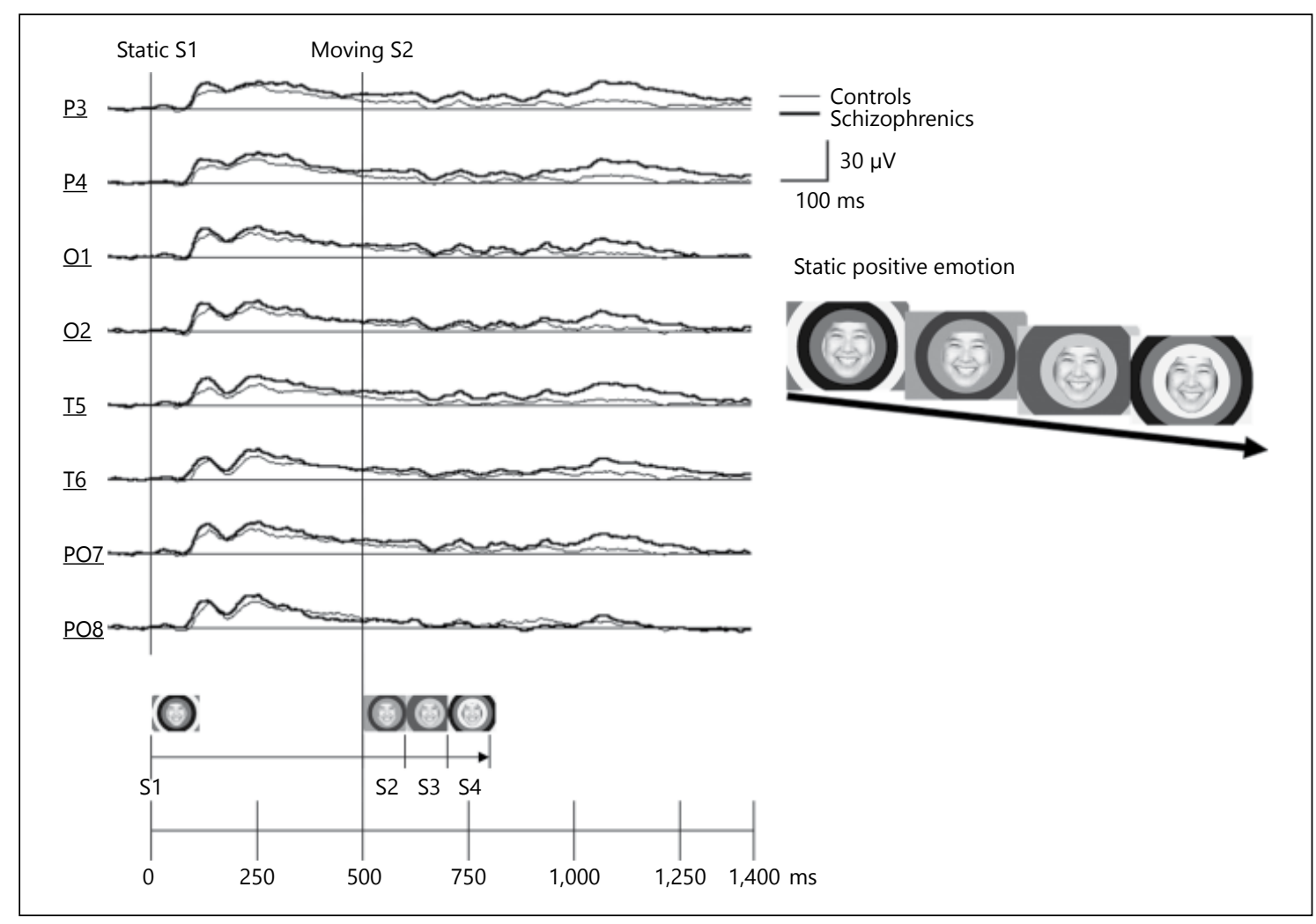

Fig. 7. Grand average waveforms for static positive emotion.

Fig. 8. Moving S2-N200 latencies (a) and moving S2-P100-N200 peak-to-peak amplitudes (b) for static and dynamic emotions (averaged across emotions and electrodes). Moving S2-N200 latencies for moving stimuli were prolonged in comparison with those for static stimuli in controls, but there were no differences between latencies for dynamic and static stimuli in patients. Moving S2-P100-N200 peak-to-peak amplitudes for dynamic emotions were significantly greater than those for static emotions in controls, but there were no significant differences in patients. ${ }^{*} \mathrm{p}<0.05$.

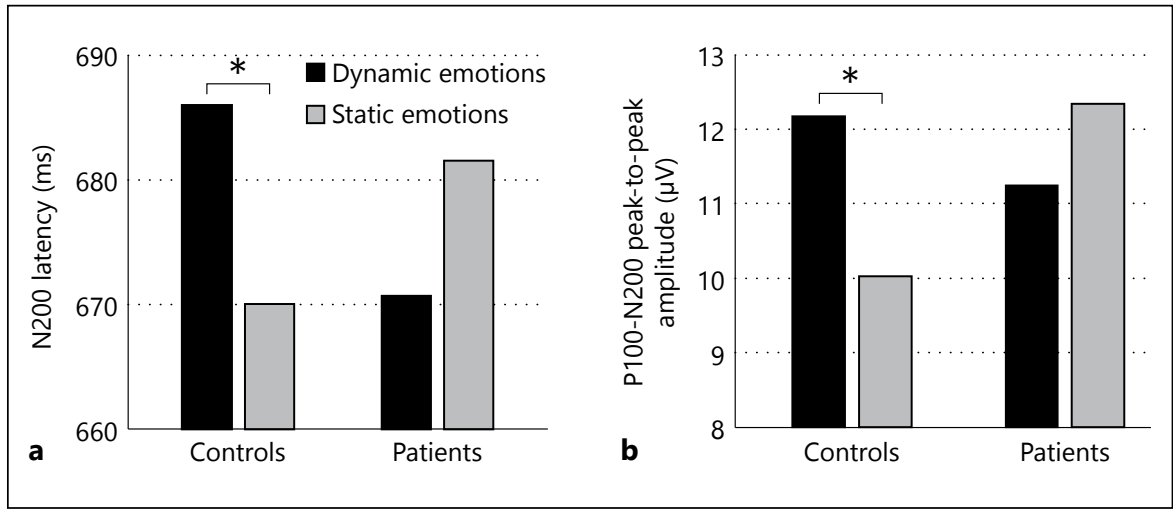

tion of the amygdala to neutral faces in schizophrenia [31, 42-44], the finding that the neural response reflected by moving S2-N200 latency and moving S2-P100-N200 peak-to-peak amplitudes was unattenuated even for static emotions in patients may coincide with 'the enhanced fear and arousal characteristic of patients experiencing psychotic symptoms' [22]. Similarly to the response in fMRI studies finding no differences between neutral and fearful faces [31, 42-44], the equivalent response to dy- namic and static emotions could potentially lead to either over- or under-attribution of emotions, depending on the context [22]. A combination of hypersensitivity to static emotions and hyposensitivity to dynamic emotions in patients might result in no differences between responses to dynamic and static stimuli, although significant differences were observed in controls.

Another speculation is that these differences in ERP profiles between controls and patients may be attributed 
Fig. 9. Correlation between moving S2N200 latencies for dynamic negative emotion and PANSS general psychopathology scale scores. A significant negative correlation was observed between moving S2N200 latencies for dynamic negative emotion and PANSS general psychopathology scale scores.

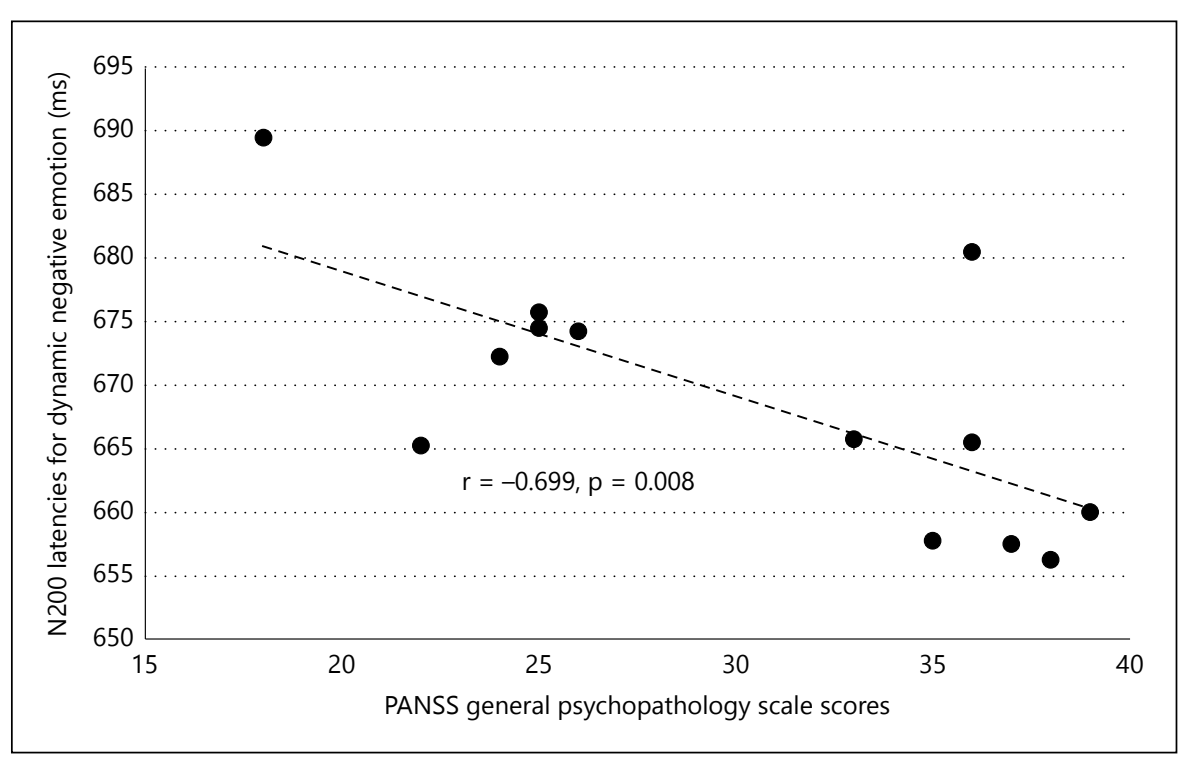

to the attentional distractibility of patients to the moving background with static emotions, as reflected by unattenuated moving S2-N200 latencies and moving S2-P100N200 peak-to-peak amplitudes for dynamic emotions. Schizophrenic patients may be abnormally distractible and thus have an increased tendency to react to irrelevant stimuli [68-70].

With regard to the relationship between the ERP measures and clinical symptoms, a significant negative correlation was observed between moving S2-N200 latencies for dynamic negative emotion and the general psychopathology scale score of PANSS, i.e. the shorter the N200 latencies were, in contrast to the tendency of controls, the graver was the symptom severity. In previous studies, no clear relationship of facial recognition deficits or facial emotion processing deficits and symptom status has emerged [22]. Some studies have reported deficits to be unrelated to symptoms $[3,4,71]$, others that impairment is greatest in association with positive symptoms [10, 72 , 73 ], some that it is greatest in association with negative symptoms $[5,74]$ and still others that impairment is greatest in association with overall severity of symptoms [6]. The exact relationship between symptoms and facial emotion recognition remains to be resolved.

This study has some limitations. First, we did not assess the performance of facial emotion processing or control vigilance because we did not ask the subjects to respond to the stimuli; the task was completely passive. In the experimental design of the present study, we intended to exclude the effect of nonspecific cognitive factors, including motivation to the task or attentional demands.
Second, a significant negative correlation was observed between moving S2-N200 latencies for dynamic negative emotion and the general psychopathology scale score of PANSS; however, we found no valence effect of emotions in patients. Some studies have identified an impairment in negative emotions in general [75], others have found impairment to be greatest for particular negative emotions such as fear $[42,71]$, and some have identified no valence effect on impairment [4]. Third, we could not match years of education and the parental socioeconomic status between the groups. Further work is needed to clarify these issues. To understand the cognitive strategies specific to schizophrenic patients for recognizing faces and dynamic facial expressions in greater detail, multiple approaches combined with other neuroimaging techniques may be needed.

\section{Conclusions}

We investigated the brain response during the processing of dynamic emotions in schizophrenic patients and healthy controls using ERP. N200 latencies and P100N200 peak-to-peak amplitudes in controls were prolonged or greater for response to dynamic emotions in comparison with those for static stimuli, but there were no significant differences between dynamic and static stimuli responses in patients. A combination of hypersensitivity to static emotions and hyposensitivity to dynamic emotions in patients might result in an absence of differences between their responses to dynamic and static stimuli. 


\section{References}

$>1$ Radua J, Phillips ML, Russell T, Lawrence N, 16 Allison T, McCarthy G, Nobre A, Puce A, BelMarshall N, Kalidindi S, El-Hage W, McDonald C, Giampietro V, Brammer MJ, David AS, Surguladze SA: Neural response to specific components of fearful faces in healthy and schizophrenic adults. Neuroimage 2010;49:939-946.

$>2$ Phillips ML, David AS: Facial processing in schizophrenia and delusional misidentification: cognitive neuropsychiatric approaches. Schizophr Res 1995;17:109-114.

$>3$ Addington J, Addington D: Facial affect recognition and information processing in schizophrenia and bipolar disorder. Schizophr Res 1998;32:171-181.

4 Kucharska-Pietura K, David AS, Masiak M, Phillips ML: Perception of facial and vocal affect by people with schizophrenia in early and late stages of illness. Br J Psychiatry 2005;187: 523-528.

5 Martin F, Baudouin JY, Tiberghien G, Franck $\mathrm{N}$ : Processing emotional expression and facial identity in schizophrenia. Psychiatry Res 2005; 134:43-53.

$\checkmark 6$ Penn DL, Combs DR, Ritchie M, Francis J, Cassisi J, Morris S, Townsend M: Emotion recognition in schizophrenia: further investigation of generalized versus specific deficit models. J Abnorm Psychol 2000;109:512-516.

$>7$ Morrison RL, Bellack AS, Mueser KT: Deficits in facial-affect recognition and schizophrenia. Schizophr Bull 1988;14:67-83.

$>8$ Mandal MK, Pandey R, Prasad AB: Facial expressions of emotions and schizophrenia: a review. Schizophr Bull 1998;24:399-412.

$>9$ Edwards J, Jackson HJ, Pattison PE: Emotion recognition via facial expression and affective prosody in schizophrenia: a methodological review. Clin Psychol Rev 2002;22:789-832.

$>10$ Hall J, Harris JM, Sprengelmeyer R, Sprengelmeyer A, Young AW, Santos IM, Johnstone EC, Lawrie SM: Social cognition and face processing in schizophrenia. Br J Psychiatry 2004; 185:169-170.

11 Baas D, van't Wout M, Aleman A, Kahn RS: Social judgement in clinically stable patients with schizophrenia and healthy relatives: behavioural evidence of social brain dysfunction. Psychol Med 2008;38:747-754.

$\checkmark 12$ Pinkham AE, Hopfinger JB, Pelphrey KA, Piven J, Penn DL: Neural bases for impaired social cognition in schizophrenia and autism spectrum disorders. Schizophr Res 2008;99: 164-175.

$>13$ Williams LM, Loughland CM, Green MJ, Harris AW, Gordon E: Emotion perception in schizophrenia: an eye movement study comparing the effectiveness of risperidone vs. haloperidol. Psychiatry Res 2003;120:13-27. 14 Green MJ, Williams LM, Davidson D: Visual
scanpaths to threat-related faces in deluded schizophrenia. Psychiatry Res 2003;119:271285.

$>15$ Haxby JV, Hoffman EA, Gobbini MI: The distributed human neural system for face perception. Trends Cogn Sci 2000;4:223-233. ger A: Human extrastriate visual cortex and the perception of faces, words, numbers, and colors. Cereb Cortex 1994;4:544-554.

17 McCarthy G, Puce A, Gore JC, Allison T: Face-specific processing in the human fusiform gyrus. J Cogn Neurosci 1997;9:605610.

18 Phillips ML, Young AW, Senior C, Brammer M, Andrew C, Calder AJ, Bullmore ET, Perrett DI, Rowland D, Williams SC, Gray JA, David AS: A specific neural substrate for perceiving facial expressions of disgust. Nature 1997;389:495-498.

19 Puce A, Allison T, Bentin S, Gore JC, McCarthy G: Temporal cortex activation in humans viewing eye and mouth movements. J Neurosci 1998;18:2188-2199.

20 Puce A, Allison T, Gore JC, McCarthy G: Face-sensitive regions in human extrastriate cortex studied by functional MRI. J Neurophysiol 1995;74:1192-1199.

21 Phan KL, Wager T, Taylor SF, Liberzon I: Functional neuroanatomy of emotion: a meta-analysis of emotion activation studies in PET and fMRI. Neuroimage 2002;16:331348.

22 Marwick K, Hall J: Social cognition in schizophrenia: a review of face processing. $\mathrm{Br} \mathrm{Med}$ Bull 2008;88:43-58.

23 Lee CU, Shenton ME, Salisbury DF, Kasai K, Onitsuka T, Dickey CC, Yurgelun-Todd D, Kikinis R, Jolesz FA, McCarley RW: Fusiform gyrus volume reduction in first-episode schizophrenia: a magnetic resonance imaging study. Arch Gen Psychiatry 2002;59:775-781.

24 Onitsuka T, Niznikiewicz MA, Spencer KM, Frumin M, Kuroki N, Lucia LC, Shenton ME, McCarley RW: Functional and structural deficits in brain regions subserving face perception in schizophrenia. Am J Psychiatry 2006; 163:455-462.

25 Quintana J, Wong T, Ortiz-Portillo E, Marder SR, Mazziotta JC: Right lateral fusiform gyrus dysfunction during facial information processing in schizophrenia. Biol Psychiatry 2003;53:1099-1112.

$>26$ Honea R, Crow TJ, Passingham D, Mackay CE: Regional deficits in brain volume in schizophrenia: a meta-analysis of voxel-based morphometry studies. Am J Psychiatry 2005; 162:2233-2245.

27 Crespo-Facorro B, Kim J, Andreasen NC, O'Leary DS, Bockholt HJ, Magnotta V: Insular cortex abnormalities in schizophrenia: a structural magnetic resonance imaging study of first-episode patients. Schizophr Res 2000; 46:35-43.

28 Glenthoj A, Glenthoj BY, Mackeprang T, Pagsberg AK, Hemmingsen RP, Jernigan TL, Baare WF: Basal ganglia volumes in drug-naive first-episode schizophrenia patients before and after short-term treatment with either a typical or an atypical antipsychotic drug. Psychiatry Res 2007;154:199-208.
29 Shenton ME, Dickey CC, Frumin M, McCarley RW: A review of MRI findings in schizophrenia. Schizophr Res 2001;49:1-52.

30 Wright IC, Rabe-Hesketh S, Woodruff PW, David AS, Murray RM, Bullmore ET: Metaanalysis of regional brain volumes in schizophrenia. Am J Psychiatry 2000;157:16-25.

31 Aleman A, Kahn RS: Strange feelings: do amygdala abnormalities dysregulate the emotional brain in schizophrenia? Prog Neurobiol 2005;77:283-298.

32 Bediou B, Henaff MA, Bertrand O, Brunelin J, d'Amato T, Saoud M, Krolak-Salmon P: Impaired fronto-temporal processing of emotion in schizophrenia. Neurophysiol Clin 2007;37:77-87.

33 Campanella S, Montedoro C, Streel E, Verbanck P, Rosier V: Early visual components (P100, N170) are disrupted in chronic schizophrenic patients: an event-related potentials study. Neurophysiol Clin 2006;36:71-78.

$>34$ Herrmann MJ, Ellgring H, Fallgatter AJ: Early-stage face processing dysfunction in patients with schizophrenia. Am J Psychiatry 2004;161:915-917.

35 Ibanez A, Riveros R, Hurtado E, Gleichgerrcht E, Urquina H, Herrera E, Amoruso L, Reyes MM, Manes F: The face and its emotion: right N170 deficits in structural processing and early emotional discrimination in schizophrenic patients and relatives. Psychiatry Res 2012;195:18-26.

36 Lee SH, Kim EY, Kim S, Bae SM: Event-related potential patterns and gender effects underlying facial affect processing in schizophrenia patients. Neurosci Res 2010;67:172180.

37 Lynn SK, Salisbury DF: Attenuated modulation of the N170 ERP by facial expressions in schizophrenia. Clin EEG Neurosci 2008;39: 108-111.

38 Turetsky BI, Kohler CG, Indersmitten T, Bhati MT, Charbonnier D, Gur RC: Facial emotion recognition in schizophrenia: when and why does it go awry? Schizophr Res 2007;94: 253-263.

39 Wynn JK, Jahshan C, Altshuler LL, Glahn DC, Green MF: Event-related potential examination of facial affect processing in bipolar disorder and schizophrenia. Psychol Med 2013; 43:109-117.

$>40$ Wynn JK, Lee J, Horan WP, Green MF: Using event-related potentials to explore stages of facial affect recognition deficits in schizophrenia. Schizophr Bull 2008;34:679-687.

41 Chen Y, Norton D, Ongur D, Heckers S: Inefficient face detection in schizophrenia. Schizophr Bull 2008;34:367-374.

42 Hall J, Whalley HC, McKirdy JW, Romaniuk L, McGonigle D, McIntosh AM, Baig BJ, Gountouna VE, Job DE, Donaldson DI, Sprengelmeyer R, Young AW, Johnstone EC, Lawrie SM: Overactivation of fear systems to neutral faces in schizophrenia. Biol Psychiatry 2008;64:70-73. 
43 Holt DJ, Kunkel L, Weiss AP, Goff DC, 53 Gomes BD, Souza GS, Saito CA, da Silva Filho Wright CI, Shin LM, Rauch SL, Hootnick J, Heckers S: Increased medial temporal lobe activation during the passive viewing of emotional and neutral facial expressions in schizophrenia. Schizophr Res 2006;82:153-162.

-44 Surguladze S, Russell T, Kucharska-Pietura K, Travis MJ, Giampietro V, David AS, Phillips ML: A reversal of the normal pattern of parahippocampal response to neutral and fearful faces is associated with reality distortion in schizophrenia. Biol Psychiatry 2006;60:423431.

45 Adolphs R: Cognitive neuroscience of human social behaviour. Nat Rev Neurosci 2003;4: 165-178.

46 Hirayasu Y, Tanaka S, Shenton ME, Salisbury DF, DeSantis MA, Levitt JJ, Wible C, Yurgelun-Todd D, Kikinis R, Jolesz FA, McCarley RW: Prefrontal gray matter volume reduction in first episode schizophrenia. Cereb Cortex 2001;11:374-381.

-47 Buchanan RW, Vladar K, Barta PE, Pearlson GD: Structural evaluation of the prefrontal cortex in schizophrenia. Am J Psychiatry 1998;155:1049-1055.

48 Burns J, Job D, Bastin ME, Whalley H, Macgillivray T, Johnstone EC, Lawrie SM: Structural disconnectivity in schizophrenia: a diffusion tensor magnetic resonance imaging study. Br J Psychiatry 2003;182:439-443.

49 Baas D, Aleman A, Vink M, Ramsey NF, de Haan EH, Kahn RS: Evidence of altered cortical and amygdala activation during social decision-making in schizophrenia. Neuroimage 2008;40:719-727.

50 Watanabe S, Kakigi R, Puce A: Occipitotemporal activity elicited by viewing eye movements: a magnetoencephalographic study. Neuroimage 2001;13:351-363.

51 Langton SR, Watt RJ, Bruce II: Do the eyes have it? Cues to the direction of social attention. Trends Cogn Sci 2000;4:50-59.

52 Watanabe S, Kakigi R, Miki K, Puce A: Human MT/V5 activity on viewing eye gaze changes in others: a magnetoencephalographic study. Brain Res 2006;1092:152-160.
M, Rodrigues AR, Ventura DF, Silveira LC: Cone contrast influence on components of the pattern onset/offset VECP. Ophthalmic Physiol Opt 2010;30:518-524.

54 Puce A, Syngeniotis A, Thompson JC, Abbott DF, Wheaton KJ, Castiello U: The human temporal lobe integrates facial form and motion: evidence from $\mathrm{fMRI}$ and ERP studies. Neuroimage 2003;19:861-869.

55 Suzuki A, Kirino E: Combined LORETA and fMRI study of recognition of eyes and eyemovement in schizophrenia; in Nakagawa $M$, Hirata K, Koga Y, Nagata K (eds): Frontiers in Human Brain Topology. Amsterdam, Elsevier Science, 2004, pp 348-351.

56 Olfson M, Ascher-Svanum H, Faries DE, Marcus SC: Predicting psychiatric hospital admission among adults with schizophrenia. Psychiatr Serv 2011;62:1138-1145.

57 American Psychiatric Association: Diagnostic and Statistical Manual of Mental Disorders, ed 4, rev. Washington, American Psychiatric Association, 1994.

58 Kay SR, Fiszbein A, Opler LA: The positive and negative syndrome scale (PANSS) for schizophrenia. Schizophr Bull 1987;13:261276.

59 Biehl M, Matsumoto D, Ekman P, Hearn V, Heider K, Kudoh T, Ton V: Matsumoto and Ekman's Japanese and Caucasian facial expressions of emotion (JACFEE): reliability data and cross-national differences. J Nonverbal Behav 1997;21:3-21.

60 Matsumoto D, Ekman P: Japanese and Caucasian Facial Expressions of Emotion (JACFEE) and Neutral Faces (JACNeuF). San Francisco, Department of Psychology, San Francisco State University, 1988.

61 Ekman P, Friesen WV: Pictures of Facial Affect. Palo Alto, Consulting Psychologist Press, 1976.

62 Watanabe S, Kakigi R, Koyama S, Kirino E: Human face perception traced by magnetoand electro-encephalography. Brain Res Cogn Brain Res 1999;8:125-142.

63 Walker-Smith GJ, Gale AG, Findlay JM: Eye movement strategies involved in face perception. Perception 1977;6:313-326.

64 Green MJ, Phillips ML: Social threat perception and the evolution of paranoia. Neurosci Biobehav Rev 2004;28:333-342.
65 Shimizu T, Shimizu A, Yamashita K, Iwase M, Kajimoto O, Kawasaki T: Comparison of eyemovement patterns in schizophrenic and normal adults during examination of facial affect displays. Percept Mot Skills 2000;91: 1045-1056.

66 Green MJ, Williams LM, Davidson D: Visual scanpaths and facial affect recognition in delusion-prone individuals: increased sensitivity to threat? Cogn Neuropsychiatry 2003;8: 19-41.

67 Cabral-Calderin Y, Mendoza-Quinones R, Garcia A, Caballero A, Dominguez M, Reyes MM: Effect of quetiapine treatment on facial emotion recognition deficits in schizophrenia patients. Schizophr Res 2010;119:275-276.

68 Flekkoy K: Neurophysiological aspects of distractability in schizophrenics. A theoretical analysis. Acta Psychiatr Scand 1980;61:461472.

69 Oepen G, Funfgeld M, Holl T, Zimmermann P, Landis T, Regard M: Schizophrenia - an emotional hypersensitivity of the right cerebral hemisphere. Int J Psychophysiol 1987;5: 261-264.

70 Serper MR, Davidson M, Harvey PD: Attentional predictors of clinical change during neuroleptic treatment in schizophrenia. Schizophr Res 1994;13:65-71.

71 Edwards J, Pattison PE, Jackson HJ, Wales RJ: Facial affect and affective prosody recognition in first-episode schizophrenia. Schizophr Res 2001;48:235-253.

72 Weniger G, Lange C, Ruther E, Irle E: Differential impairments of facial affect recognition in schizophrenia subtypes and major depression. Psychiatry Res 2004;128:135-146.

73 Poole JH, Tobias FC, Vinogradov S: The functional relevance of affect recognition errors in schizophrenia. J Int Neuropsychol Soc 2000; 6:649-658.

74 Sachs G, Steger-Wuchse D, Kryspin-Exner I, Gur RC, Katschnig H: Facial recognition deficits and cognition in schizophrenia. Schizophr Res 2004;68:27-35.

75 Brune M: Emotion recognition, 'theory of mind,' and social behavior in schizophrenia. Psychiatry Res 2005;133:135-147. 